\title{
THE EFFECTIVENESS OF A PYRIPROLE (125 MG/ML) AND A METAFLUMIZONE (150 MG/ML) COMBINED WITH AMITRAZ (150 MG/ML) SPOT-ON TREATMENT IN PReVenting Phlebotomus PeRniciosus from feeding ON DOGS
}

\author{
THOMAS C.*, ROQUES M.* \& FRANC M.*
}

\section{Summary:}

A controlled clinical trial was performed to assess the effectiveness of a pyriprole $(125 \mathrm{mg} / \mathrm{ml})$ and a metaflumizone $(150 \mathrm{mg} / \mathrm{ml})$ combined with amitraz $(150 \mathrm{mg} / \mathrm{ml})$ spot-on treatment (recommended dosage) in preventing adult female sandflies (Phlebotomus perniciosus) from feeding on dogs. Sandfly mortality was also assessed. Twelve beagle dogs were used in the study. Prior to treatment they were checked for their attractiveness to sandflies, ranked accordingly to generate partner triplets of equivalent sensitivity to sandflies: four control dogs, four treated with the pyriprole and four with the metaflumizone spoton. The dogs were challenged with 50 unfed adult female sandflies (8-10 days old), in cages for one hour on Day 1 and Day 7 . The sandflies were checked for blood feeding and mortality at one hour, 24 hours and 48 hours after exposure to the dogs. A very poor anti-feeding effect (near $7 \%$ ) was seen on sandflies with the metaflumizone combined with amitraz and no antifeeding effect was seen with pyriprole. The sandfly mortality effect as a result of exposure to treated dogs was under $20 \%$ for the two spot-on. The two formulations could not be proposed in a leishmaniosis prevention program.

KEY WORDS : metaflumizone, pyriprole, Phlebotomus, sandflie control, antifeeding, dog, spot-on.

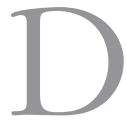
eltamethrin and permethrin are used to prevent culex and sandflies from feeding on dogs (Killick-Kendrick et al., 1997; Xiong et al., 1994; Xiong et al., 1995). Products with these active ingredients have the claim "antifeeding effect on culex and sandflies" and also the claim "treatment and prevention of fleas and ticks infestation".

Two new formulations with new active ingredient (pyriprole alone, a phenylpyrazole insecticide and metaflumizone, a semicarbazone insecticide combined with an acaricide the amitraz) used in spot-on appeared on the market. The claims are similar "treatment and prevention of fleas and ticks infestation". The formulation is applied on the skin (one point), then the active ingredient enters the lipid layer of the skin and spread rapidly across the all surface of the dog.

* UMR 181 Physiopathologie et Toxicologie Expérimentales, INRAENVT. École Nationale Vétérinaire, 23, chemin des Capelles, 31076 Toulouse Cedex, France.

Correspondence: Michel Franc.

Tel.: 33 (0)5 61193873 - Fax: 33 (0)5 61193971.

E-mail: m.franc@envt.fr
Résumé : Pyriprole et asSOCIATION MÉTAFLuMiZONE-AMITRAZ Étude de l'activité anti-gorgement vis-à-VIS de PhLebotomus PERNICIOSUS SUR LE CHIEN TRAITÉ PAR CES FORMULATIONS SPOT-ON

Cet essai avait pour but d'étudier l'efficacité de deux spoton destinés au chien - pyriprole $(125 \mathrm{mg} / \mathrm{ml})$ et métaflumizone $1150 \mathrm{mg} / \mathrm{mll}$ associée à l'amitraz $(150 \mathrm{mg} / \mathrm{mll}$ - sur les phlébotomes (effet létal et effet antigorgement). 12 chiens ont été utilisés. Ils ont été répartis en trois lots de quatre en fonction de leur attractivité pour les femelles de phlébotomes. Un lot a été traité avec le spot-on au pyriprole, un lot avec la métaflumizone associée à de l'amitraz, le dernier lot étant le lot témoin non traité. Un et sept jours après le traitement, les chiens ont été soumis pendant une heure à des infestations par 50 femelles à jeun de Phlebotomus perniciosus âgées de 8-10 jours. L'état de gorgement a été observé une heure après, la mortalité notée 24 et 48 heures après chaque infestation. L'effet antigorgement est faible (7\%) pour la métaflumizone associée à l'amitraz et nulle pour le pyriprole. La mortalité entraînée par les deux produits est d'environ $20 \%$. Ces deux formulations ne présentent pas d'intérêt dans un programme de prévention de la leishmaniose.

MOTS CLÉS : métaflumizone, pyriprole, Phlebotomus, prévention phlébotome, antigorgement, chien, spoton.

It appears interesting for the user to know in leishmaniosis area if these new formulations are able to protect dogs from sand flies biting.

\section{MATERIALS AND METHODS}

\section{Dogs}

Wwelve adult male and female Beagle dogs, weighing between 8.5 and $12.1 \mathrm{~kg}$ were housed individually in stainless steel cages in an environmentally controlled room, fed a commercial dog food with water supplied ad libitum. All dogs were identified by ear tattoo. After two weeks acclimatization and before treatment, all were challenged with unfed adult female sandflies, ranked according to the number of sandflies biting then into four partner triplets of approximately equal sensitivity and randomly allocated to one of the three groups (treated with pyriprole spot-on, treated with metaflumizone-amitraz spoton or left untreated) using a random $\mathrm{ABC}$ sequence. 
None of the dogs had received any antiparasitic treatment, which had ectoparasiticidal activity within two months of the start of acclimatization.

Dogs were observed regularly throughout the study.

\section{SANDFLIES MAINTENANCE AND SUPPLY}

Phlebotomus perniciosus (Diptera, Psychodidae), originally sourced from Lisbona (Dr Carlos PIRES-Portugal), were cultured at ENVT using a 5-week egg to adult cycle. 50 adult females 8-10 days old were used to challenge each dog.

\section{EXPERIMENTAL PROCEDURE}

The dogs were treated with the unit label dose of each formulation respecting the laboratories recommendations. For each product, the unit label dose of solution was applied topically by first parting the hair on the neck between the shoulders and applying the formulation directly on a single spot on the skin.

Dogs of the group A were untreated (Control group); dogs of group B were treated with a pyriprole spot-on (Prac-tic $137.5 \mathrm{mg}^{\circledR}$ or Prac-tic $275 \mathrm{mg}^{\circledR}$ depending of the weight of the dog, Novartis) at the dosage of 13.7$24.9 \mathrm{mg} / \mathrm{kg}$; the dogs of group C were treated with a metaflumizone-amitraz spot-on (PromerisDuo $499.5 \mathrm{mg}+$ $499.5 \mathrm{mg}^{\circledR}$ Fort Dodge) at the dosage of $39-46 \mathrm{mg} / \mathrm{kg}$ of each active ingredient.

The sandfly challenge assessment cages $(60 \mathrm{~cm} \times$ $40 \mathrm{~cm} \times 50 \mathrm{~cm}$ ) were constructed from sandflies netting mounted on a wooden frame and placed in environmentally controlled rooms. Fifty unfed female sandflies were placed in each of these four hours before introducing the dogs, which were immobilised using ketamine (Imalgene ${ }^{\circledR} 9 \mathrm{mg} / \mathrm{kg}$, Merial) and medetomidine (Domitor ${ }^{\circledR} 4 \mu \mathrm{g} / \mathrm{kg}$, Pfizer) anaesthesia throughout the one hour exposure to the sand flies.

Three partner pairs were challenged with sandflies at any one time and all challenge assessments were done in virtual darkness except for some borrowed light to enable the dogs to be observed throughout the challenge period.

At the end of the exposure period the dogs were checked carefully for any sandflies remaining on them, then removed from the cage and allowed to regain full consciousness. All the live female sandflies collected, observed and classified (engorged or unengorged) and placed in holding cages for observation 48 hours. The dead present in the assessment cage were counted and classified (engorged or unengorged). The sandflies were fed on sugar-water and checked for mortality at 24 and 48 hours after exposure to the dog.

\section{DATA ANALYSIS}

The data collected at each time point were: number of live and engorged sandflies, number of live and unengorged sandflies, number of dead and engorged sandflies, number of dead and un-engorged sandflies. Effects were assessed on a group basis (total numbers per treatment group). The statistical unit was the individual dog. The mortality and the anti-feeding rates were determined for each treatment group at each occasion of exposure of the dogs to sandflies (at 24 hours and at 48 hours after exposure) as follows:

$\frac{\text { total number of dead sandflies }}{\text { total number of recovered sandflies }}=$ mortality rate
$\frac{\text { total number of unfed sandflies }}{\text { total number of recovered sandflies }}=$ anti-feeding rate

The mortality effect and the anti-feeding effect of the treatment was calculated for each time point of assessment by the following formula:

(mortality rate in treated dogs)-

$\frac{(\text { mortality rate in untreated } \operatorname{dogs})}{1-(\text { mortality rate in untreated dogs })}=$ mortality effect

(anti-feeding rate in treated dogs)-

$\frac{\text { (anti-feeding rate in untreated } \operatorname{dog} s \text { ) }}{1 \text {-(anti-feeding rate in untreated dogs) }}=$ anti-feeding effect

Statistical analyses: comparisons between groups were performed using the non parametric test Kruskal-Wallis $(\mathrm{p}<0.05)$

\section{RESULTS}

The results (Fig. 1) show that the experimental infestations with Phlebotomus perniciosus were successful, with a low percentage of mortality ( 4 to $18 \%$ ) of the insects exposed on untreated dogs. Between 41 and 48 mosquitoes were steel alive 48 hours after each exposure to the control dogs.

The mortality effect 48 hours after exposure to the treated dogs was approximately $20 \%$ on D 1 and $10 \%$ on D7 with pyriprole and 16-11\% with metaflumizone. (Table I and Fig. 1). The mean number of alive female

\begin{tabular}{ccccr}
\hline \multirow{2}{*}{$\begin{array}{c}\text { Day } \\
\text { infestation }\end{array}$} & \multicolumn{2}{c}{$\mathbf{2 4}$ hours } & \multicolumn{2}{c}{$\mathbf{4 8}$ hours } \\
\cline { 2 - 5 } & Pyriprole & Metaflumizone & Pyriprole & Metaflumizone \\
\hline D1 & 7.20 & 0.00 & 19.86 & 6.32 \\
D10 & 2.10 & 3.60 & 9.21 & 11.13 \\
\hline
\end{tabular}

Table I. - Sandflie mortality effect (\%). 


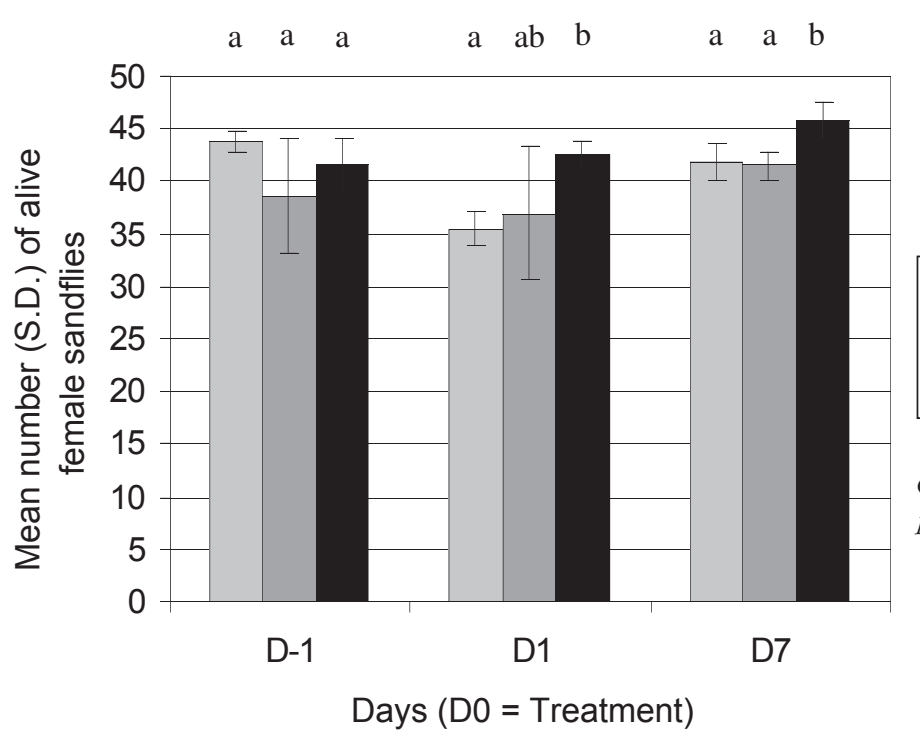

\section{$\square$ Pyriprole \\ $\square$ Metaflumizone \\ - Control}

Groups with different superscripts are statistically significant at $p<0.05$



Table II. - Anti-feeding effect (\%).

is statistically different between the pyriprole treated group and the control group $(\mathrm{p}<0.05)$ on days 1 and 7 and on day 7 for the metaflumizone group comparing to the control group. In the same conditions the percentage of engorged females in the control group was between 84 and $86 \%$ and approximately $92 \%$ in the pyriprole treated group and $82 \%$ in the metaflumizone treated group. (Fig. 2). The observed percentages of feeding did not differ significantly between the two treated groups and the untreated group on day 1 and $7(\mathrm{p}<0.05)$.
The metaflumizone anti-feeding effect of sandflies after one hour exposure to treated dogs were approximately $7 \%$ on D1 and D7. No antifeeding effect was observed with the pyriprole. (Table I and Fig. 2).

\section{DISCUSSION AND CONCLUSION}

The two new spot-on pyriprole $(125 \mathrm{mg} / \mathrm{ml})$ and metaflumizone $(150 \mathrm{mg} / \mathrm{ml})$ combined with amitraz $(150 \mathrm{mg} / \mathrm{ml})$ are very efficient against fleas and ticks (Barnett et al., 2007; Hellmann et al., 2007; Rugg et al., 2007; Schuele et al., 2007).

In our trial conducted in the good clinical practice, we don't observe a significant difference in the killing effect between the two formulations 16 to $20 \%$ at day 1 and 9 to $11 \%$ on day 7 . Only with the metaflumizone we observe a no significant antifeeding effect (near $7 \%$ ) 
against Phlebotomus perniciosus one and seven days after the treatment at the recommended dosage. Consequently the dogs are not protected from being bitten by sandflies. So the two formulations could not be proposed in a canine leishmaniosis prevention program.

\section{ACKNOWLEDGEMENTS}

The authors thank Bob and Mireille Kilick-Kendrick, Carlos Pires, Hervé Hoste, Solange Vermot, Sonia Gounaud, Émilie Bouhsira and Agnès

Batard for their assistance.

\section{REFERENCES}

Arther R., Caroll S., Cruthers L., Slone R. \& Young D. Topically applied products to inhibit the feeding of mosquitos on dogs. Proceeding $48^{\text {th }}$ Annual Meeting of the American Association of Veterinary Parasitologists, 2003, 30-31.

Barnett S., Luempert L., Quezada A., Schuele G., Strehlau G. \& DOHERTY P. The efficacy of pyriprole topical solution against the cat flea, Ctenocephalides felis, on dogs. $21^{\text {st }}$ International Conference of the World Association for the Advancement of Veterinary Parasitology, 2007, August 1923, Gent.

Hellmann K., Adler K., Parker L., Pfister K., Delay R.L. \& Rugg D. Evaluation of the efficacy and safety of a novel formulation of metaflumizone plus amitraz in dogs naturally infested with fleas and ticks in Europe. Veterinary Parasitology, 2007, 15 (150), 239-245.

Kildick-Kendrick R., Killick-Kendrick M., Focheux C., Dereure J., Puech M.P. \& Cadiergues M.C. Protection of dogs from bites of phlebotomine sand flies by deltamethrin collars for control of canine leishmaniasis. Medical \& Veterinary Entomology, 1997, 11, 105-111

LUCIENTES J. Laboratory observations on the protection of dogs from the bites of Phlebotomus perniciosus with Scalibor RProtector Bands: preliminary results. Canine Leishmaniasis: an update (ed. by R. Killick-Kendrick), Hoechst Roussel Vet, Wiesbaden, 1999, 92-94.

Maroli M, Mizzoni V, Siraguza C., Df'orazi A. \& Gradoni L. Evidence for an impact on the incidence of canine leishmaniosis by the mass use of deltamethrin-impregnated dog collars in southern Italy. Medical and Veterinary Entomology 2001, 15, 358-363.

Malzoumi-Gavgani A.S., Hodjati M.H., Mohite H. \& Davies C.R. Effect of insecticide impregnated dog-collars on incidence of zoonotic visceral leishmaniasis in Iranian children: a matched cluster randomised trial. Lancet, 2002, 360, 374-379.

Mencke N., Volf P., Volfovaz V \& Stannezck D. Repellent efficacy of a combination containing imidacloprid and permethrin against sand flies (Phlebotomus papatasi) on dogs, Parasitology Research, 2003, 90, 108-111.

Rugg D., Hair J.A., Everett R.E., Cunningham J.R. \& Carter L. Confirmation of the efficacy of a novel formulation of metaflumizone plus amitraz for the treatment and control of fleas and ticks on dogs. Veterinary Parasitology, 2007 (in press).

Schuele G., Barnett S., Cavaliero T., Bapst B., Luempert L., Strehlau G., Young, D. R. \& Moran C. The Efficacy of pyriprole topical solution against tick (Rhipicephalus sanguineus, Ixodes ricinus, Dermacentor reticulatus) infestations on dogs. $21^{\text {st }}$ International Conference of the World Association for the Advancement of Veterinary Parasitology, 2007, August 19-23, Gent.

Xiong G.H., Jin C.F., Chen X.Z., Su Z.W. \& Hong Y. Deltamethrin bath of domestic dog in the prevention of sandfly bite. Endemic Disease Bulletin, 1994, 9, 32-34.

Xiong G.H., Jin C.F., Hong Y., Su Z.W., Xue P., Xie W., Zhang A., LI G. \& GAO B. Studies on the deltamethrin-medicated bath of domestic dogs for interrupting visceral leishmaniasis transmission. Abstracted from Zhongguo Ji Sheng Hong Xue Ji Sheng Chong Bing Za Zi, 1995, 13, 178-181.

Reçu le 14 décembre 2007 Accepté le 20 décembre 2007

\section{PARASITE}

\section{ADDENDUM AUX INSTRUCTIONS AUX AUTEURS Règles de taxinomie}

Dans la page de titre, les taxa des parasites et des hôtes seront suivis soit de l'autorité du taxon et de la date de création, soit de n. gen. et/ou n. sp. Les catégories supra-familiale et familiale suivront entre parenthèses. Dans le chapitre "Matériel et Méthodes", la classification choisie pour les hôtes sera précisée. Les données biologiques (prévalence, charge parasitaire, coparasitisme...) seront données dans la section taxinomique ainsi que l'étymologie du nom du taxon.

\section{ADDENDUM TO INSTRUCTIONS TO AUTHORS Taxonomic rules}

In the title page, the taxa of parasites and their hosts will be followed either by the authority of the taxon and the date of creation, or by $n$. gen. or/and n. sp. Suprafamily and family categories will follow in brackets.

In the chapter "Material \& Methods", the choice of the classification for the host will be specified. Biological data (prevalence, burden, coparasitism...) will be provided in the taxonomic section as well as the etymology of the name of the taxon. 